\title{
独立成分分析法を用いた肌色解析とそのシミ解析への応用 Image Analysis of Skin Color Using Independent Component Analysis and Its Application to Melanin Pigmentation Analysis
}

\author{
小島伸俊 \\ 花王株式会社 \\ ビューティケア研究センター \\ 干131-8501 東京都墨田区文花 2-1-3 \\ Nobutoshi OJIMA \\ Global R\&D Beauty Creation, \\ Kao Corporation \\ 2-1-3 Bunka Sumida-ku, TOKYO \\ 131-8501, JAPAN
}

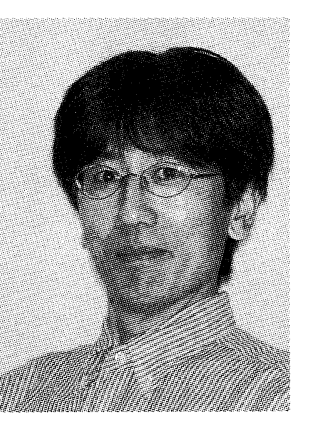

上村隆明

花王株式会社

ビューティケア研究センター

厂131-8501 東京都墨田区文花 2-1-3

Takaaki UEMURA

Global R\&D Beauty Creation, Kao Corporation

2-1-3 Bunka Sumida-ku, TOKYO 131-8501, JAPAN

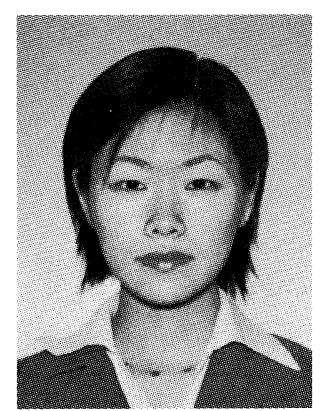

沖山夏子

花王株式会社

ビューティケア研究センター

厂131-8501 東京都墨田区文花 2-1-3

Natsuko OKIYAMA

Global R\&D Beauty Cosmetics,

Kao Corporation

2-1-3 Bunka Sumida-ku, TOKYO

131-8501, JAPAN

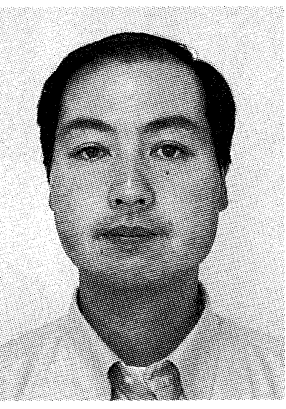

\section{堀 公彦}

花王株式会社

ビューティケア研究センター

厂131-8501 東京都墨田区文花 2-1-3

Kimihiko HORI

Global R\&D Beauty Cosmetics,

Kao Corporation

2-1-3 Bunka Sumida-ku, TOKYO

131-8501, JAPAN

論文要旨：肌のシミやソバカスの定量的解析のための新手法を紹介する。肌画像に独立成分分析法を適用 することで，メラニン色素成分とへモグロビン色素成分さらには陰影情報を分離抽出することが可能となっ た。今回, メラニン色素由来の色素沈着 (シミ) の定量的解析システムとして, 個々のシミの詳細解析用と 顔全体のシミ解析用の 2 種類を構築し, シミの季節変化, 加齢変化, 美白剂の連用に伴う変化を定量的に解 析した結果を報告する。

Abstract: A practical skin color analysis technique is introduced for evaluating melanin pigmentation such as freckles. Skin color images are analyzed by extracting hemoglobin, melanin and shading components using the independent component analysis. We propose two practical measurement systems. One is for analyzing individual pigmentations on the skin, and the other is for investigating the distribution of pigmentations on the facial skin. The seasonal changes and age-related changes of pigmentations were analyzed as well as the change after use of a whitening essence.

Key words: skin color, skin texture, melanin, hemoglobin, pigmentation, independent component analysis

\section{1 はじめに}

消費者の意識調査 ${ }^{11}$ によると, 20 代〜 50 代女性の肌 悩みのなかで，シミ・ソバカス・くすみ等の肌色に関す る悩みは常に上位に挙げられている。このような消費者 連絡者: 小島伸俊

E-mail : ojima.nobutoshi@kao.co.jp
の要望に応えるべく肌色の改善を目標とした美容施術, 化粧品開発，さらにはその評価法に関する研究が盛んに 行われている。また, 昨年日本香粧品学会化粧品機能評 価法検討委員会より新規効能取得のための医薬部外品美 白機能評価試験ガイドラインが作成されており，色素沈 着測定法についてょり精度の高い測定が望まれている。 さて, 従来から肌色を測定する手法として, 色彩計や 
分光光度計による色彩值 ( $\mathrm{L}^{*} \mathrm{a}^{*} \mathrm{~b}^{*}$ 等) が用いられてい る2)。ところが，得られた色彩值たとえば明度 $\left(\mathrm{L}^{*}\right)$ を 指標としたシミの濃さを解析する場合には, メラニン色 素の変化だけでなくへモグロビン色素の変化の影響を受 けてしまうこと（複数の色素情報の混在）, シミの形状 や大きさ解析ができないこと（2 次元分布計測の困難 性）が大きな課題であった。最近, 津村らが提案した肌 画像の独立成分分析法により, メラニン濃度計測および 2 次元分布解析が可能となってきた。本報では, 独立成 分分析法を応用しシミの解析を行った結果を紹介する。

\section{2 独立成分分析法を用いた肌色解析}

津村ら ${ }^{3-4}$ は通常の RGB カメラで撮影した肌画像に独 立成分分析法を適用することで，メラニン成分画像，へ モグロビン成分画像の算出方法を提案している。偏光画 像を用いる以外はとくに照明光の色や照明幾何条件の制 約がないため，幅広い応用が期待されている。

撮影に際して, カメラと照明の前に偏光フィルタを設 置した偏光撮影系を使用した (Fig. 1(a) ) ${ }^{5)}$ 。2 枚の偏光 フィルタの偏光面を平行および垂直に設置後に撮影した 一組の画像から, 内部散乱画像と表面反射画像を得るこ とができる（Fig. 1(b))。ここで得られた内部散乱画像 にはシミも含めた肌色情報が含まれている5)。

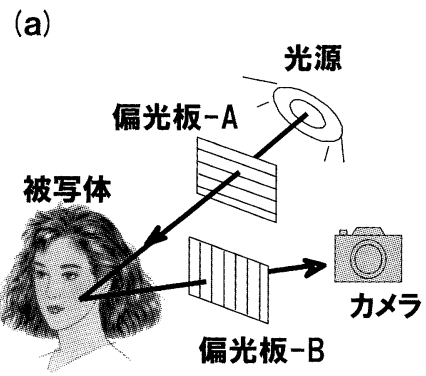

(b)

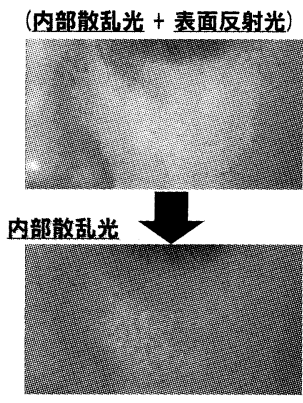

\section{表面反射光}

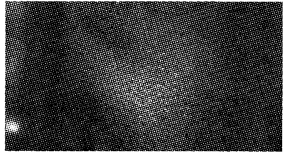

Fig. 1 偏光を用いた肌画像の撮影方法

(a) 偏光を用いた撮影系，（b)肌の反射光成分

次に, 偏光撮影系で得られた内部散乱画像を用いてメ ラニン成分，へモグロビン成分を分離するステップを説 明する。まず，肌色が主に 2 色素成分からなりそれぞれ が表皮層，真皮層に独立に存在する 2 層モデルを仮定す る。照明ムラが十分少ない小領域を考えた場合，各画素 $(\mathrm{x}, \mathrm{y})$ の肌色 $C(\mathrm{x}, \mathrm{y})$ の対数值はメラニン色素成分 $\sigma m$ と ヘモグロビン成分 $\sigma h$ とがそれぞれの色素量 $\mathrm{m}(\mathrm{x}, \mathrm{y}), \mathrm{h}$ $(\mathrm{x}, \mathrm{y})$ にて線形的に足しあわされた表現が可能となる。 ただし，Bias はバイアス成分（定数）である。

$-\log \{C(\mathrm{x}, \mathrm{y})\}=\sigma m \cdot \mathrm{m}(\mathrm{x}, \mathrm{y})+\sigma h \cdot \mathrm{h}(\mathrm{x}, \mathrm{y})+$ Bias ただし, $C(\mathrm{x}, \mathrm{y})=[\operatorname{Red}(\mathrm{x}, \mathrm{y}), \operatorname{Green}(\mathrm{x}, \mathrm{y}), \operatorname{Blue}(\mathrm{x}, \mathrm{y})]$ 実際，肌画像のほほ領域（100 画素 $\times 100$ 画素）の画 素值をプロットした際にほぼ平面上に分布しており主に 2 成分で表現できることがわかった（Fig. 2)。なお，平 面を構成する 2 成分は独立成分分析法により決定した。 実際，独立成分分析法 ${ }^{6} に よ り$ 抽出された色素成分が適 切か否かを判断するために，紫外線照射 2 週間後のメラ ニン色素斑およびニコチン酸メチルによる血行促進部位 を解析 ${ }^{7-8)}$ したところ，それぞれの色素パターンが第 1 , 第 2 独立成分に分離抽出できることがわかった。以後, 抽出された 2 つの独立成分をメラニン成分，モグロビン 成分と呼び，メラニン成分画像 $\mathrm{m}(\mathrm{x}, \mathrm{y})$ およびへモグロ ビン成分画像 $\mathrm{h}(\mathrm{x}, \mathrm{y})$ を画像として表示した。なお，顔 画像に適用する際に発生する照明ムラや陰影情報を除去 する手法 ${ }^{79}$ を導入することで解析精度の向上を実現した (Fig. 3)。

(a)

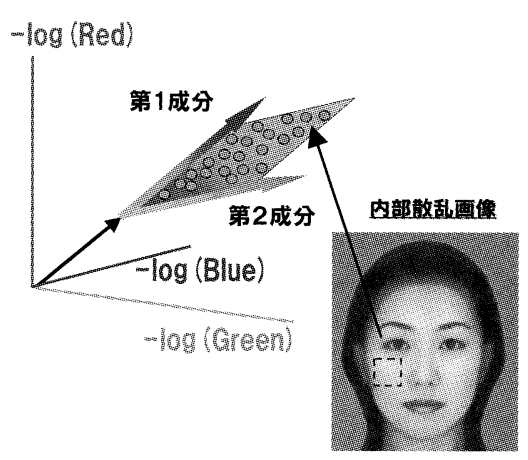

Fig. 2 独立成分分析法を用いた肌画像の解析 (a)肌色分布 (3 次元色空間), (b) 分離後の色素成分画像

(a)
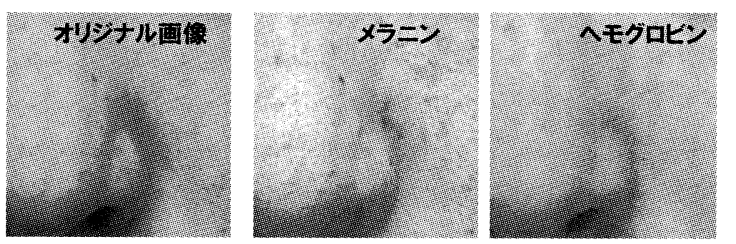

(b)
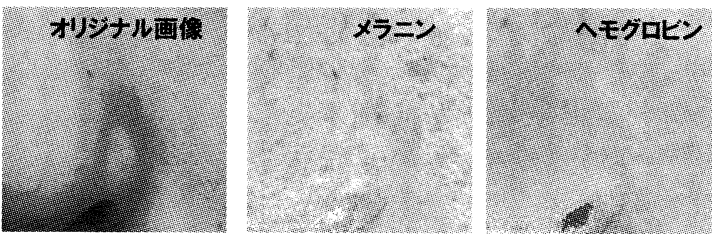

Fig. 3 独立成分分析法による色素成分分離結果 （a）陰影除去を行っていない場合，（b）陰影除去を 行った提案法 


\section{3 シミの解析システム}

前述の独立成分分析法を色素沈着（シミ）計測に応用 するため，専用の解析システムを 2 種類構築した。1つ は個々のシミの解析システム（デジタルマイクロスコー プ）であり，他方は顔全体のシミ・ソバカスの解析シス テム（顔撮影装置）である（Fig. 4）。今回は前者につい てのみ報告する。

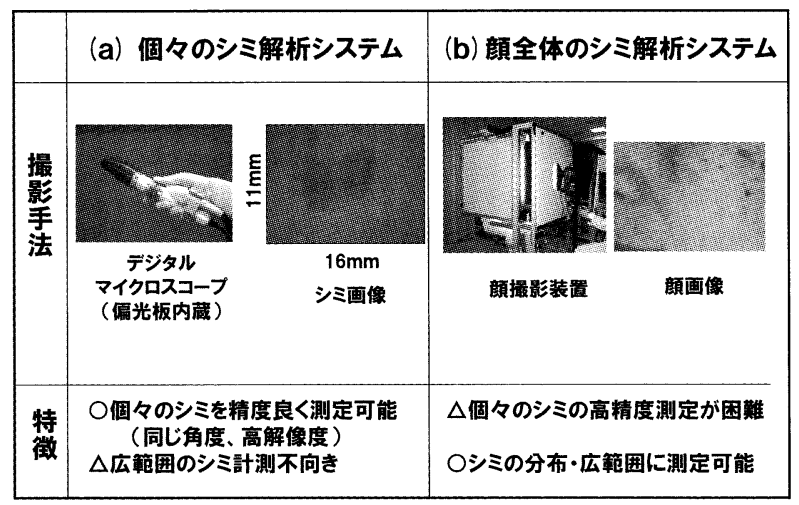

Fig. 4 シミ解析システム

(a) 個々のシミ解析用システム, (b) 顔全体のシミ 解析用システム

デジタルマイクロスコープは偏光フィルタを内蔵して おり ${ }^{10-11)}, 11 \mathrm{~mm} \times 16 \mathrm{~mm}$ 領域のシミの内部拡散画像 を拡大取得することが可能である。さらに，センサー先 端部にガラス板を装着することにより皮膚の隆起による 測定誤差を軽減でき，シミの面積・形状を繰り返し安定 な測定を可能とした。

\section{4 シミの実態解析への応用}

シミの実態および化粧品の連用効果時の変化を解析す るため, 以下の条件にてシミの調査を行った。とくに， 被験者本人が気にするシミを個々に追跡し, その面積変
化や濃度変化の解析を行った。

- 対象者人数： 20 代 60 代の女性 105 名

·対象：本人の気にするシミ $1 \sim 3$ 個 / 1 人

・測定期間： 2004 年 9 月〜 2005 年 6 月 ( 3 力月間隔)

- 解析項目：(1)シミの季節変化 (濃さ, 大きさ変化), (2)シミの年代別変化, (3)美白美容液（カモミラ ET 配合処方）の機能評価

解析に際しては，シミを含む撮影画像に独立成分分析 法を適用し，得られたメラニン画像のノイズ除去および 2 值化処理をして, シミの面積またその領域の濃度計測 を行った（Fig. 5)。3つの解析項目に対する結果は次の とおりであった。

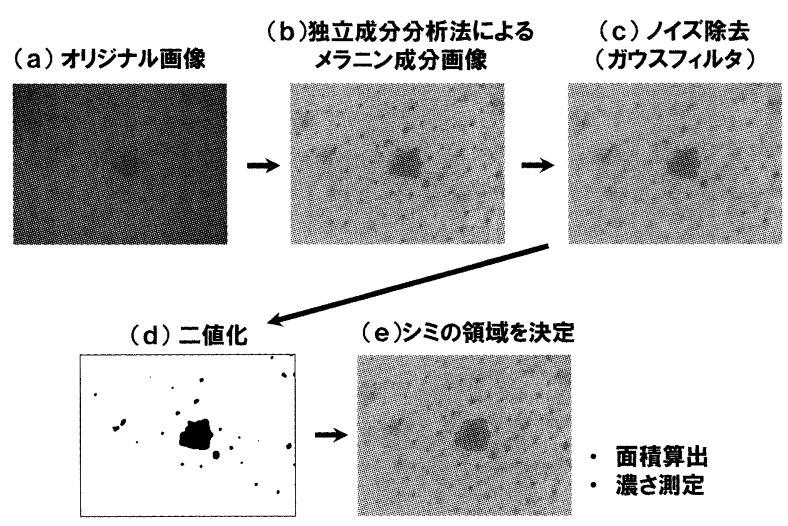

Fig. 5 シミ解析の流れ

（1) 季節変化：シミの面積は 6 月に有意に大きくなる こと，シミの濃さは 3 月にかけて薄くなり 6 月に かけて濃くなることがわかった（Fig. 6）。また， 20 代や 40 代とは異なり 60 代では 3 月にシミが あまり薄くならず夏場（6月）に濃くなった。

(2) 9 月における年代別変化：年代が高くなるほどシ ミが濃く，大きくなることが確認できた。従来報 告 ${ }^{13)}$ されている顔全体のシミの変化と同様の結果 (a)

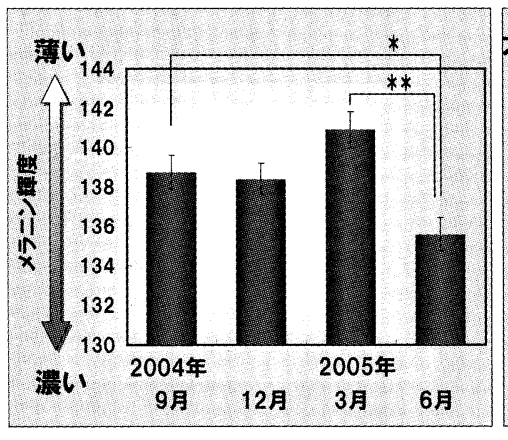

(b)

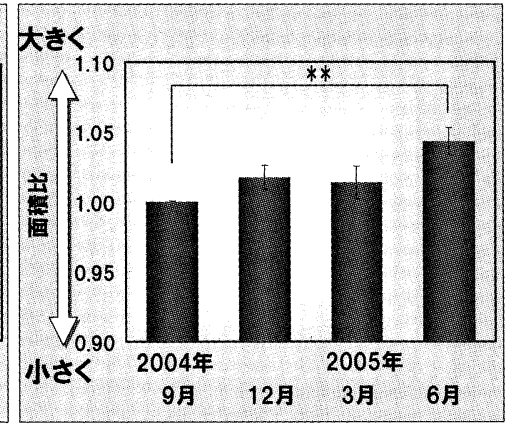

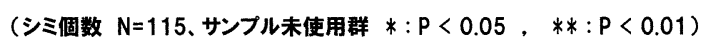

Fig. 6 シミの季節変化 (a)シミの濃さ, (b) シミの面積比 
(a)

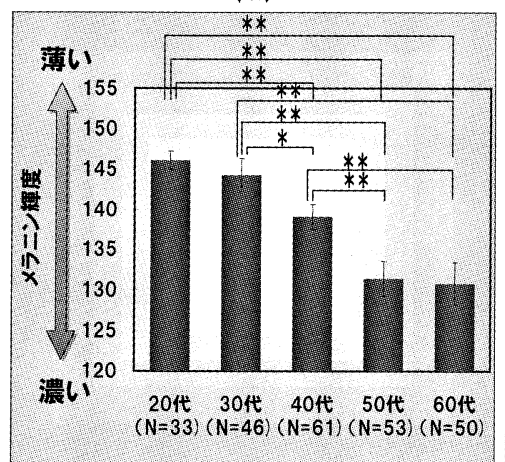

(b)

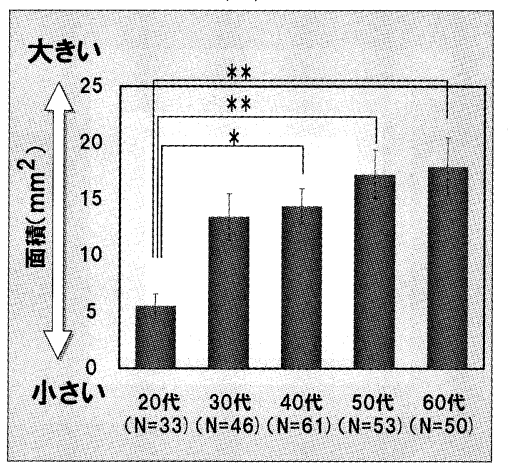

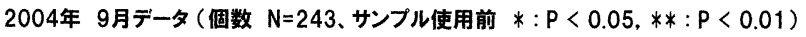

Fig. 7 シミの年齢変化（a)シミの濃さ，（b）シミの面積比

であった（Fig. 7)。

(3) 美白剂使用群のシミの変化：9月〜 12 月の 3 力 月間連用後のシミの面積変化（N=68 個）を解析 した結果，美白剤未使用群のシミ（N=115 個）に 比べ有意に面積が減少した（Fig. 8)。

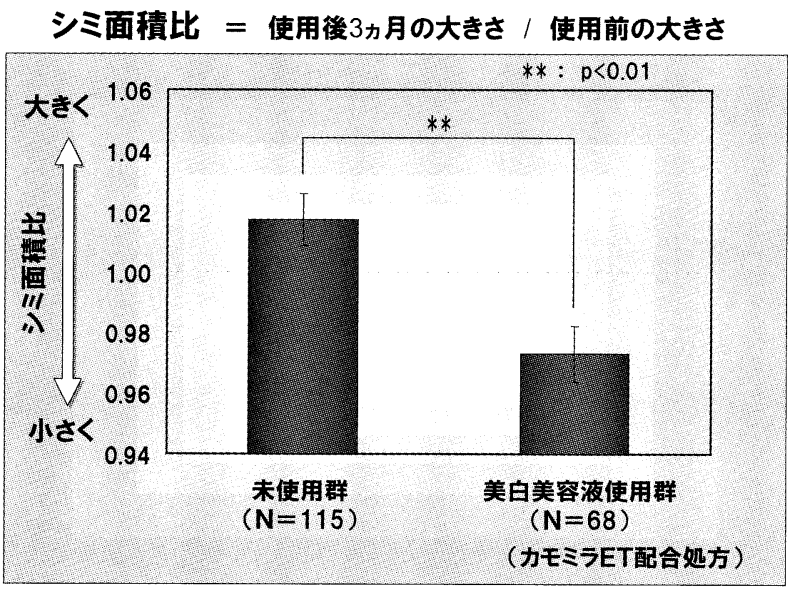

Fig. 8 美白剤連用に伴うシミの変化

今回，デジタルマイクロスコープを用いたシミ解析シ ステムを紹介したが，撮影領域を超える大きなシミや広 域に存在するしみ・そばかすの解析に困難が残る。顔全 体の解析システムとの併用による課題の補完が望まし w。

\section{5 おわりに}

独立成分分析法によるメラニン色素画像を用い，シミ の定量化方法について紹介した。今回は割愛したが，解 析により蓄積したシミや肌色の動態をモデル化し，個々 人の肌画像でシミ増減や肌色の変化シミュレーションを 行う試みがなされ始めている ${ }^{12)}$ 。今後とも肌色やシミな どの変化の豊富な蓄積が望まれるとともに，黒人から白 人までの幅広い肌色に対しての適用可能性の検討など,
肌色解析手法自体の開発が望まれている。

なお本原稿は，2007 年 2 月 21 日の第 31 回 SCCJ セミ ナー『アンチエイジング化粧品開発の新潮流〜評価系か ら素材・処方の設計，開発まで〜』の講演資料を一部修 正したものである。

\section{謝辞}

本研究は, 花王 (株) 美容センターと千葉大学工学部情 報画像工学科 三宅・津村 - 中口研究室との共同研究で ある。南浩治氏，三宅教授，津村助教授，中口助手，学 生の皆様に心より感謝します。

\section{文献}

1）赤崎秀一ら，日本香粧品化科学会誌，17，6 (1993).

2）田島譲二，羽石秀昭，小島伸俊，塚田正人，画像電子 学会誌, 31, 768 (2002).

3) N. Tsumura, H. Haneishi \& Y. Miyake, J. Opt. Soc. Am. A, 16, 2169 (1999).

4）津村，羽石，三宅，画像ラボ，1999 (2), 1 (1999).

5）小島伸俊, 羽石秀昭, 三宅洋一, 日本写真学会誌，56, 264 (1993).

6) S. Roberts \& R. Everson, Independent Component Analysis Principles and Practice, Cambridge University Press (2001).

7) N. Tsumura, N. Ojima, K. Sato, M. Shiraishi, H. Shimizu, H. Nabeshima, S. Akazaki, K. Hori \& Y. Miyake, "Image-based skin color and texture analysis/ synthesis by extracting hemoglobin and melanin information in the skin", In Proceedings of SIGGRAPH2003, 22 (3), 770-9 (2003).

8) N. Ojima, N. Tsumura, S. Akazaki, K. Hori \& Y. Miyake, J. Imaging Sci. Technol., 48, 222 (2004).

9）清水，津村，小島，三宅，陰影の影響を受けない肌の 色素成分計測法，第 49 回応物予稿集, 987 (2002).

10）上村隆明，沖山夏子，武内栄次郎，執印美加，凉松 淳，南浩治，小島伸俊，堀公彦，独立成分分析法を用 いたシミ評価法の開発, 第 31 回日本香粧品学学術大会 講演要旨, 28 (2006). 
11）沖山夏子, 小山内宰, 上村隆明, 武内栄次郎, 南浩治, 小島伸俊, 堀公彦, 日本香粧品学会誌, 投稿中 (2007).

12) N. Tsumura, T. Nakaguchi, N. Ojima, K. Takase, S. Okaguchi, R. Usuba, M. Shiraishi, N. Okiyama, K. Hori
\& Y. Miyake, Real-time image-based control of skin melanin texture, ACM SIGGRAPH2005 sketches (2005).

13）新井清一, 原由起子, 三村邦雄, 永澤久直, 西島靖, J. Soc. Cosmet. Chem. Jpn., 23 (1), 31 (1989). 